\title{
Internal Factors Influence on Project Management Maturity Assessment
}

\author{
Muhammad S Ahmed
}

Eastern Michigan University

United States

\begin{abstract}
The study acts as a pilot research to investigate the influence of organization's internal dynamics on PMM assessment levels and to outline a methodology that can help us to quantify it. It aims to analyze the influence of organizations' internal dynamics on project management maturity, (PMM), assessments and how they can change the assessment results. Specifically, it addresses the impact of internal organizational influences, like organization culture, leadership \& leadership hierarchy and emotional stability on the assessments of organization project management maturity. The methodological research approach for this study was a survey of 129 professionals. These professionals represent both manufacturing and service sectors industries that utilizes project management extensively. Data was analysed using multiple regression models with SPSS data processingThe results show that organization's internal factors significantly influence project management maturity assessments. The internal forces like organization culture and leadership/ leadership hierarchy significantly increase the PMM levels while emotional stability greatly reduces the PMM levels. These results can help upper management to better understand the PMM assessment results while academics can use it to amend maturity models and for conducting a more extensive longitudinal research.
\end{abstract}

Indexing terms/Keywords :Engineering management, project management, project management maturity model, organization internal influences.

Subject Classification : Engineering Management

Type (Method/Approach):Survey

Language : English

Date of Submission : 2018-02-25

Date of Acceptance : 2018-03-20

Date of Publication : 2018-04-30

ISSN : 278-5612

Volume : 13 Issue : 1

Journal : INTENATIONAL JOURNAL OF MANAGEMENT AND INFORMATION TECHNOLOGY

Publisher : CIRWORLD

Website : https://cirworld.com

This work is licensed under a Creative Commons Attribution 4.0 International License. 


\section{Introduction}

It is a well-known fact that self and peer assessments are important aspects of "assessment for learning" practice. Just as self-assessments help people become aware of problems and areas that need to be improved, it is also true for organizations. Such self-assessments in the organization usually lead them assessing their current levels of performance, their general working environments, as well as identifying undesired working condition. Similarly, customer oriented businesses require that they are self-cognizant of their efforts and look for value in tools that provide the assessment on the quality and reliability of the product being produced. As these organizations learn the benefits of becoming more project oriented in their tasks, it becomes important for them to know, and understand, if what they are doing is better than pre-project management inception or quite possibly the opposite. It is therefore important to learn if there are factors that can distorts such performance assessments. Such distortions might force organization to opt for implementing unwanted project management tools and practices in desperation and hope for improvement.

In late 90s, Project Management Institute published Organizational Project Management Maturity Model $\left(\mathrm{OPM}{ }^{\circledR}\right)$. The objectives of OPM3®are to integrate, assess and improve project management practices, [1], [2]. This type of model allows a company to formally, evaluate its Project Management maturity by measuring according to a standard set either by the company itself or by an external agency. Today, almost every business, using project management, has some level of measurement that helps them to assess where they are in relation to how mature the business is in being a project management organization.

Most of the maturity models were originated in the 1980s when software companies sought formal ways to measure and manage the quality and reliability of software development. An external group known as the Software Engineering Institute, SEI, created a model referred to as the Capability Maturity Model, (CMM), which provided an objective and structured way for measuring the processes and practices used in the development of software by companies found in the software industry. CMM is still in use today and serves as a foundation for many other types of maturity models in businesses, including project management, [4].

In the area of project management, we find several maturity models that offer standard for quality and continuous improvement. An excellent example of a Project Management Maturity Model, (PM3), is the Kerzner's Project Management Maturity Model, which provides measures of quality and continuous improvement categorized into five levels, [4]. The goal, of course, is not to achieve a certain level and then call their maturity complete. Quite the opposite, the goal of the project maturity models, as that of Kerzner's, is to achieve a level where the project-driven organizations are in a constant state of improvement in their methodologies toward quality and reliability, [4].

To understand the premise and intent of PM3, it is important to review literature, which gives visibility and insight into what these project maturity models are achieving and how they are helping organizations to improve. Mullaly's, [5], in a Longitudinal Analysis of Project Management Maturity raised questions about what exactly influences the results that come from Project Management Maturity Assessments, (PMMA). Mullaly, [5], during his study, attributed government participation, greater awareness of project management and fewer stakes in project management by upper management to influence the maturity results.

Most importantly, Mullaly, [5], recognizes that when assessing maturity of project management organizations, certain internal and external factors influence PMMA. Examples of these internal factors include organizational culture, behavioural excellence and the leadership of upper management. While, external factors include the current economic, political, and market environment. Mullaly [5], study did not quantify the impact of these influences on the organizations he surveyed.

This pilot study investigated the quantitative effects of these internal influences on organization's project maturity level. The study first tested Mullaly's results, in both manufacturing and service sectors companies. Later it quantify the impact of these influences on project maturity assessment.

\section{Statement of Problem}

This research hypothesize that during the PMMA process organizational internal factors should be considered when making judgement about organizations' project management maturity. Ignoring the effect of these internal factors influences will lead to poor decisions/ conclusions by the organization about their project management capabilities, which can results in either ignoring major issues within the organization and/or overestimating their capabilities. Therefore, understanding what these influences are, in the organizations, and by what magnitude they effect the results of PMMA process, could lead to enhance conclusions of PMMA process. This will help organizations to use their resources effectively to continuously improve the quality and 
reliability of their processes. The results from this study could also be used in identifying lessons learned to avoid contamination in such assessments process.

\section{Literature Review}

Project management maturity of a company is a measure of its efficiency in completing the project, [4]. The amount of literature written on project management maturity, emphasize that organization, that view project management as a means to accomplish its goals, should be take the concepts of maturing and growing better very seriously. The Project Management Institute (PMI) makes an interesting point to address maturity by including it in the knowledge area of project quality management, [1]. This importance indicate that improvement is necessary and an organization should be motivated to achieve improvement in all aspects of project management. For this study, it is also relevant to review other literature that addresses organization's internal factors and their influence on project management maturity.

In 1987, Office of the Secretary of Defence (OSD) and the National Defence Industrial Association funded Carnegie Mellon's Software Engineering Institute, (SEI) to create a model referred to as the Capability Maturity Model, (CMM), and Capability Maturity Model Integration, (CMMI). In 1997, CMM was developed, which provides an objective and structured way for measuring the processes and practices used in the development of software, [3]. In 2003, Project management Institute developed Organizational Project Management Maturity, (OPM3®), as organizations' ability to select and manage projects in a specific way that supports their strategic needs, [2]. Crawford, [6], described a form of PM3, based on the CMM. It also goes as far as basing much of its knowledge areas on PMl's Project Management Book of Knowledge (PMBOK). The main contribution of Crawford model, [6], is the importance of a structured assessment of any organization that implements project management techniques and tools.

Smith, [7], described the relationship of knowledge management with that of organizational maturity and project management. He also makes the assertion that all project management organizations use the OPM3 model to measure maturity and effectiveness as well as updated the maturity model to address knowledge management.

Yazici, [8], dealt with project management maturity and its correlation with organization culture and studied organizations perceived performance. Yazici, [8], concluded that project management maturity should have a result-oriented view since it improves organizational competitiveness. In his work, Riallano, [9], made the assertion that the OPM3 does not address organization culture, which he believes, is imperative in assessing maturity in an organization. Riallano, [9], described four types of organizational culture, hierarchy, clan, market, and adhocracy and concluded that such organization culture integrates with PM maturity assessment as it directly correlates to the internal factors that affect several project managers.

Sawaya and Trapanese, [10], presented a maturity model that classify project management organizations in five stages. Kerzner, [3], also describes a five-stage model where PMMA process would place the organization in one of the five levels. The difference between Kerzner's model and Mullaly model, [5], is the assessment nature of maturity. Figure 1, lists Kerzner's five levels of maturity.

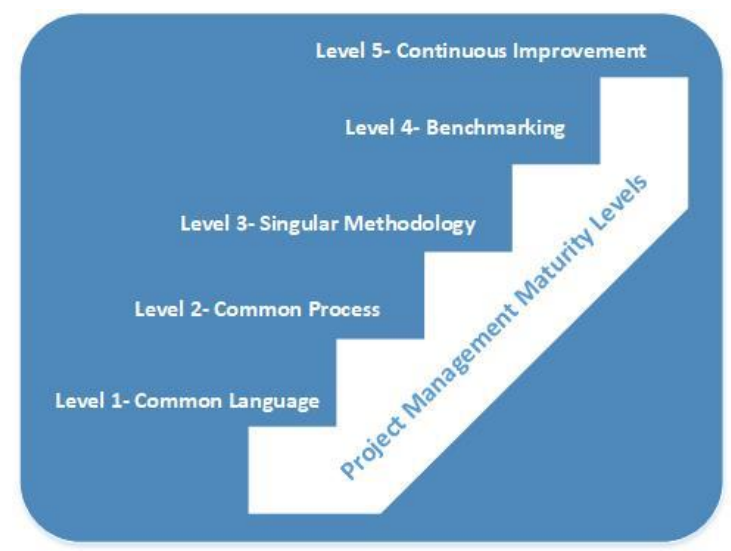

Fig. 1. Kerzner's Five Level of Maturity

The PM Maturity Model, is developed by PM Solutions, in collaboration with multiple organizations, [6]. It is an assessment tool that utilizes PMBoK's ten knowledge areas and is patterned after SEI CMM. The model 
compares project delivery with that of established best practices or against the competition. PM Maturity Model defines five levels of project management maturity for an organization, as outlined in Figure 2.

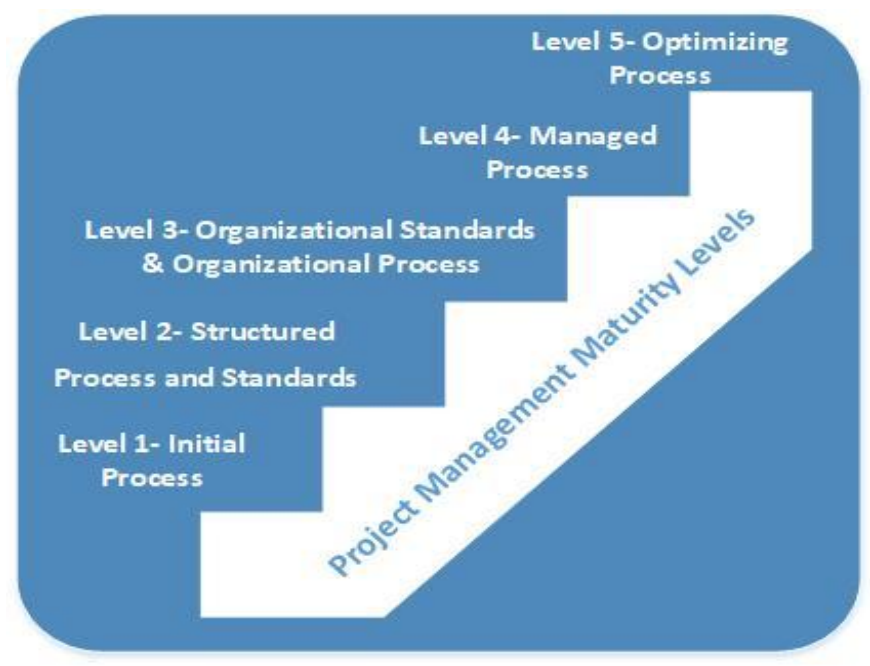

Fig. 2. Project Management Maturity Model

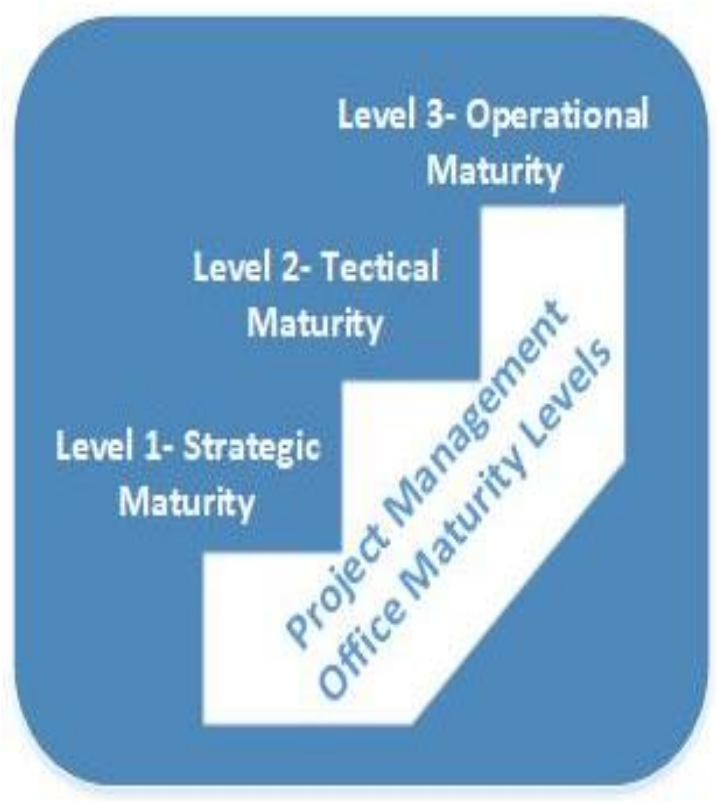

Fig. 3. Project Management Office Maturity

Couple of decade ago there was much emphasis on Project Management Office, PMO [11]. It was common saying that having a successful PMO does not indicate project management (PM) successful adaptability within an organization, [12]. Kerzner's, [3], levels of maturity deal more with how much the project management organization recognizes project management processes and tools and their implementation, thus it can be linked to, PMO's maturity model. Research on capability maturity models has concluded that there is a direct link between process management maturity and project performance, [13]. A generic PMO maturity model is defined in Figure 3.

Mullaly, [5], does an excellent job of describing the basis for the maturity model used to assess project management. He looked directly at what encompasses project management maturity by using the process areas that were assessed with CMM model, created by Humphury, [14], Figure 4. Mullaly's [5], conclusions do not indicate if he was trying to persuade the reader that what was done by him or the model he used were without its faults. Since project management maturity was in its infancy at this time, it is important to carry on Mullaly's work to find out the influences of internal and external factors and how they affect the PMM assessments. Although it is not the intent of this study to conduct a longitudinal analysis as conducted by Mullaly, this research is critical is helping to collect data on such topic. 


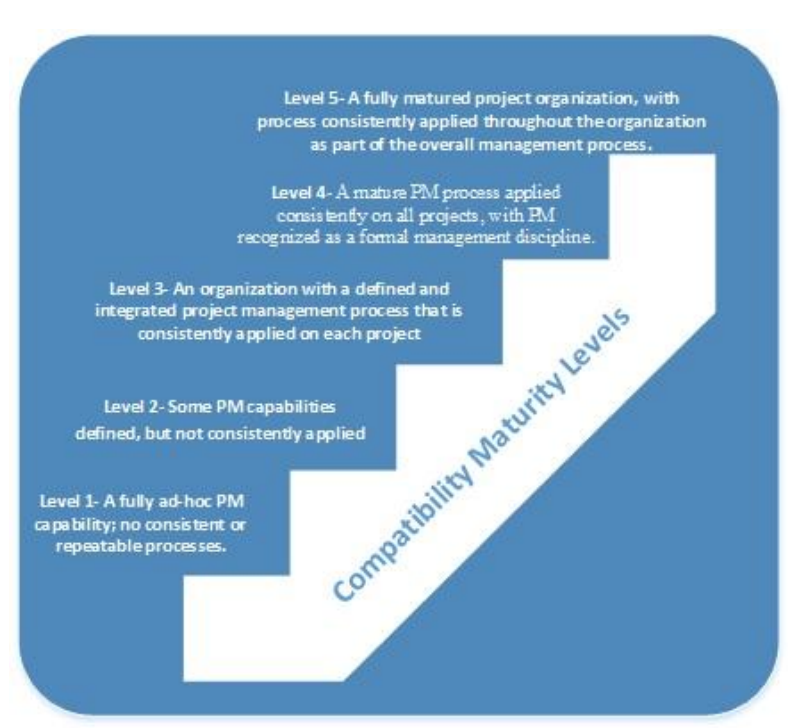

Fig. 4. Humphury Capability Maturity Model

The spider diagrams are typically used to illustrate outcomes of these maturity models, Figure 5 . The mean value of all knowledge areas and the processes are used to calculate the overall organization's project management maturity level.

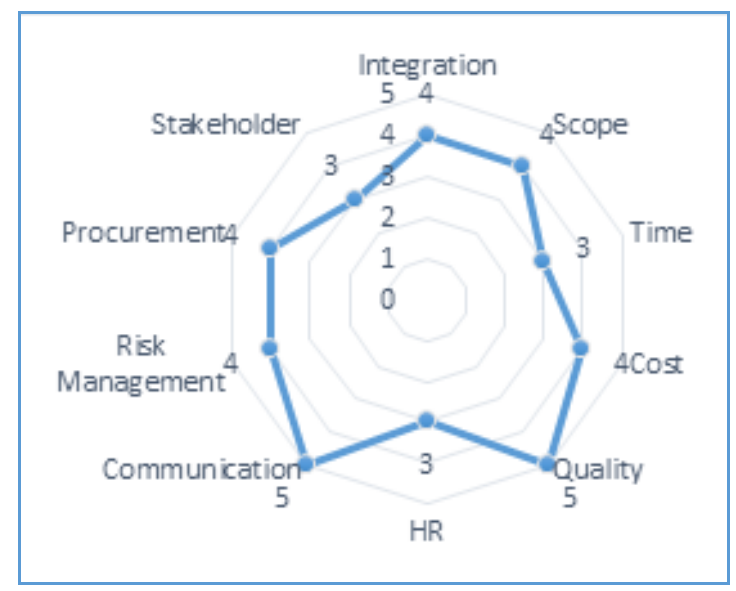

Fig 5. Project Management Maturity Illustration

In theory we can say that Mullaly's maturity model, [5], is an adaptation of the CMM and PMMM and it gives a level of achievement rather than how much the organizations recognized their maturity. It appears to define when an organization has reached a certain level of maturity and outline the practices that are carried out by the organizations that depict its maturity. However, nothing could be found in the literature to verify if any maturity model incorporates the confounding effects of internal and external factors that could change project management maturity levels. Similarly, it can also be argued that implementing PM tools and process would lead to their implementation in projects that will eventually describe the PM maturity level of the organization.

Mullaly's [5], findings were limited to using one project management maturity model, therefore the process areas chosen could not be adjusted for other areas that could have been more pertinent at the time. Perhaps modifying or possibly adding more relevant process areas to the procedures (survey) used might have achieved a better analysis of the data which seemed to have left him befuddled by his results. Again, this shows the importance of incorporating internal and external factor which even Mullaly touts at the end of his article by making conclusions about organizations seeing project management improvement as more of a fad than something they strived to incorporate in strategy, [5].

\section{Research}

\section{Research Objectives}

This research seeks to investigate the impact of organization internal influences on organization's project management maturity level assessments. The research will also concentrate on evaluating the intensity of internal influences on those assessments. Internal factors to be researched includes organizational culture, 
management hierarchy and the leadership of upper management and emotional stability. The paper will argue the fact that these internal factors affect the outcome of project management maturity levels of an organization thus correctly identifying these influences will help in fine tuning the results of PMM assessment process.

\section{Nature and significance of the problem}

The literature review has indicated the importance of further research on the influence internal and external factors on project management maturity, [5]. Both Riallano [9], and Yazici, [8], also made assertions about the impact of particular types of internal and external influences on project management maturity levels however, neither went as far to conduct a broad spectrum of internal and external factors that affect project management maturity. Because of the scope of the research, this paper will only concentrate on internal influences.

\section{Hypothesis and research questions}

Project management maturity assessments' levels are influenced by organization's internal influences. The central research questions are:

Research Question 1: Does the organization's project management maturity assessments' level is influenced by organization culture (oc) (an internal organization factor)?

$$
\begin{aligned}
& \mathrm{H}_{0}: \mu_{1}=\mu_{O C} \\
& H_{1}: \mu_{1} \neq \mu_{O C}
\end{aligned}
$$

Research Question 2: Does the organization's project management maturity assessment's level is influenced by leadership (LS) (an internal organization factor)?

$$
\begin{aligned}
& \mathrm{H}_{0}: \mu_{1}=\mu_{\mathrm{LS}} \\
& \mathrm{H}_{1}: \mu_{1} \neq \mu_{\mathrm{LS}}
\end{aligned}
$$

Research Question 3: Does the organization's project management maturity assessment's level is influenced by emotional stability, (EE) (an internal organization factor)?

$$
\begin{aligned}
& \mathrm{H}_{0}: \mu_{1}=\mu_{\mathrm{EE}} \\
& \mathrm{H}_{1}: \mu_{1} \neq \mu_{\mathrm{EE}}
\end{aligned}
$$

Research Question 4: Which specific PMI knowledge management areas in PMM assessment's levels are affected by internal factors?

\section{Research Methodology}

The paper conducted cross-sectional Descriptive study. Participants were drawn from a group of project engineers and managers in USA based project driven companies, having experience in Project management maturity models are often assessed by using the survey method, [5]. In this research, also a survey was developed and used to collect data. The research methodology is outlined in figure 6.

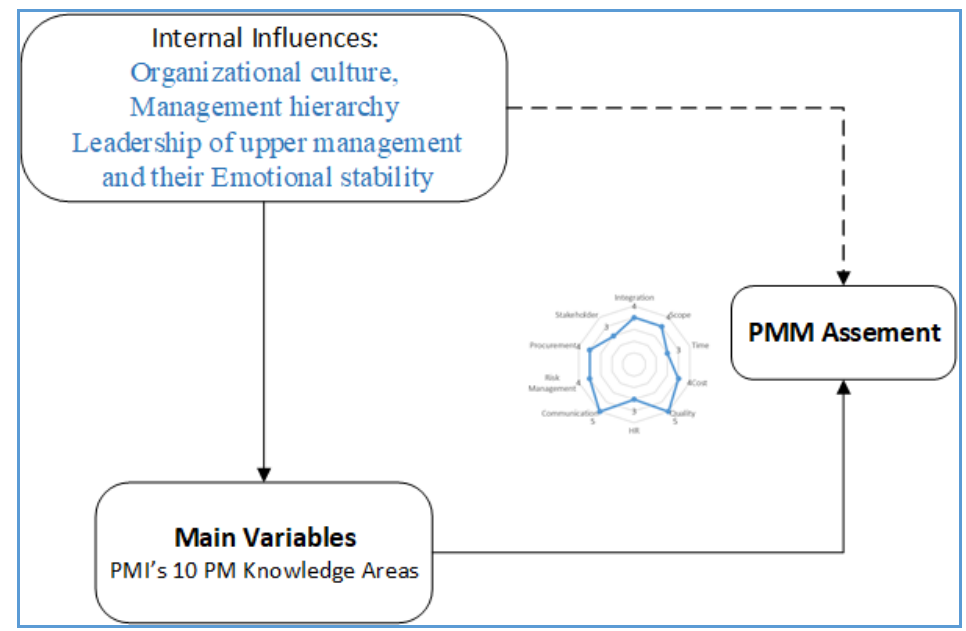

Fig 6. Research Methodology 
The survey questionnaire was developed by modifying the, UK Office of Government Commerce's [16], project management process maturity assessment methodology, and incorporating the newly defined Project Management Institute's (PMI) knowledge areas with the Likert scale to assess the maturity of project management processes.

The research survey is organized in three sessions. Session\#1 of the study focused on respondent's demography, and background information about their organizations, including their perception of the maturity level of their organization. Section\#2, of the survey, focused on the management of projects in general, to collect data needed to assess project management maturity within the following areas: Scope Management, Time Management, Cost Management, Quality Management, Human Resource Management, Integration Management, Communication Management, Risk Management, Stakeholder Management and Procurement Management. Section\#3 of the survey focused on the same areas as in Session\#2, except this time questions are targeted on projects that are influenced by internal factors identified in Table 1 . These survey questions were rated using a Likert scale of $1-5$, with one being related to lower rating (strongly disagree) and five for higher score (strongly agree).

Following Project Management Institute (PMI) OPM3, [1], and Ibbs\&Kwak, [15], guidelines, dependent variables are defined as the mean value of all maturity levels in ten knowledge areas. The ten knowledge areas are noted in Table 2 defines independent variables, along with three influence areas project management office, management oversite, and professional development management.

Table 1: Internal influences within organizations

\begin{tabular}{|c|c|c|}
\hline Organizational culture, & Leadership \& Hierarchy & Emotional Stability \\
\hline Informal project & Management hierarchy & Abrasiveness in approach \\
management & Behaviour excellence \\
Experience in PM & Upper management extra support & Team and teamwork \\
Well defined integ rated & & relation \\
processes & & \\
Innovation oriented & & \\
directives & & \\
Attention to detail & & \\
Emphasis on outcome & & \\
People Oriented & & \\
\hline
\end{tabular}

Table 2: Evaluation of organizations' project management maturity level—independent variables.

\begin{tabular}{|c|}
\hline Independent Variables \\
\hline V1 - Integration Management, V2 - Scope Management, V3 - Time Management, V4 - Cost \\
Management, V5 - Quality Management, V6 - Human Resource Management, V7 - \\
Communication Management, V8 - Risk Management, V9 - Procurement Management, V10 - \\
Stakeholder Management.
\end{tabular}

The second session of the survey has the set of questionnaire needed to calculate Project management maturity in PMl's 10 knowledge areas, example of such question is given in Table 3.

Table 3: Sample question in session 2

\begin{tabular}{|l|l|}
\hline For most of the projects within our organization, risk management is best defined by: & \\
\hline $\begin{array}{l}\text { There may be some evidence of risk management being occasionally deployed, but with minimal } \\
\text { beneficial effect. }\end{array}$ & 1 \\
$\begin{array}{l}\text { Risk management is recognized and used in some projects, but there are inconsistencies in } \\
\text { approach, commitment, and deployment. }\end{array}$ & 2 \\
\hline $\begin{array}{l}\text { Project risk management is based on a centrally defined process that is cognizant of the } \\
\text { organization's policy for the management of risks. }\end{array}$ & 3 \\
\hline $\begin{array}{l}\text { Risk management is working efficiently, is embedded, while the organizational perspective can } \\
\text { demonstrate the value of risk management. Decision making includes risk analysis. }\end{array}$ & 4 \\
\hline $\begin{array}{l}\text { Risk management is embedded in the organizational culture and underpins all decision making } \\
\text { with respect to projects. }\end{array}$ & 5 \\
\hline
\end{tabular}


The third session contains questionnaire that are similar to session two but this time instead of the general project, the issues relate to situations where projects may be influenced by internal factors outlined in Table 3 . Table 4 describes one sample question from session\#3.

Five senior PM practitioners first tested the questionnaire for clarity and validity. Based on their recommendations the survey questions were modified and was tested in a small group of project manager. The modified survey was then posted on Limesurvey, an online survey tool. As with other such studies, data collection was one of the biggest challenges. Organizations and people are reluctant to complete surveys and disclose their processes, especially when their competitions are also involved. The survey was sent out to more than 190 graduate students, in the Engineering Management and Quality Management programs. The number of full-time engineers in these two programs is about $85 \%$. Special efforts by the researchers ensured that names of organizations and their data collected remain anonymous. The survey software coded the organizations' names anonymously, thus ensuring confidentiality of proprietary data. Only the principal researchers knew the identity of these organizations.

Table 4: Sample question in session 3

\begin{tabular}{|l|c|}
\hline $\begin{array}{l}\text { In some projects, within our organization, when the upper management places extra efforts } \\
\text { on the project success, during such projects, our organization's risk management is best } \\
\text { described by. }\end{array}$ \\
\hline $\begin{array}{l}\text { There may be some evidence of risk management being occasionally deployed, but with minimal } \\
\text { beneficial effect. }\end{array}$ & 1 \\
\hline $\begin{array}{l}\text { Risk management is recognized and used in some projects, but there are inconsistencies in } \\
\text { approach, commitment, and deployment. }\end{array}$ & 2 \\
$\begin{array}{l}\text { Project risk management is based on a centrally defined process that is cognizant of the } \\
\text { organization's policy for the management of risks. }\end{array}$ & 3 \\
\hline $\begin{array}{l}\text { Risk management is working effectively, is embedded, and the value of risk management can } \\
\text { be demonstrated from the organizational perspective. Decision making includes risk analysis. }\end{array}$ & 4 \\
$\begin{array}{l}\text { Risk management is embedded in the organizational culture and underpins all decision making } \\
\text { with respect to projects. }\end{array}$ & 5 \\
\hline
\end{tabular}

\section{Research Limitations}

As with any research, this study has several limitations.

1. As the data was generated through graduate students, one can challenge the accuracy of the information gathered.

2. The best way to assess project management maturity level of any organization would require a very detailed interview with several project managers. This study, instead, uses a shorter questioner, which by no means is a proper generalization to assess many organizations and their level of project management maturity.

3. This study did not target few specific organizations for data collection and use their results to illustrate any changes in maturity level due to organization internal dynamics. Instead the study uses two large manufacturing organizations and bundle them in one sector, assuming that the within the two different corporation (within a sector), the organization internal dynamics are similar.

Based on the above limitations this study is intended to act as a pilot research to investigate the influence of organization's internal dynamics on PMM assessment levels and to outline a methodology that can help us to quantify that affect.

\section{Data Analysis}

As indicated above, it was hard to collect data. It took two semesters efforts to complete data collection. A request was emailed to 190 students, and 158 responded by completing the survey. Out of which 129 were full time employed, which makes the overall response rate of $81 \%$. The respondents represent 40 different companies, 24 in the manufacturing and 16 in the service sector. The collected data were analysed using SPSS software package.

A further analysis of the data reveals that 67 (52\%) respondents were employed by two major automotive organization or work their in-house through a contracting company. About 35 (or 27\%) of the respondents were from one automotive company, let call it T1 Automotive and 32 (or 25\%) from the T2 automotive company. Altogether $77 \%$ of the respondents were from the manufacturing sector, (automotive included) and 
$23 \%$ from the service. Figure 7 , illustrates other demography data for gender, age and years of experience in the field.

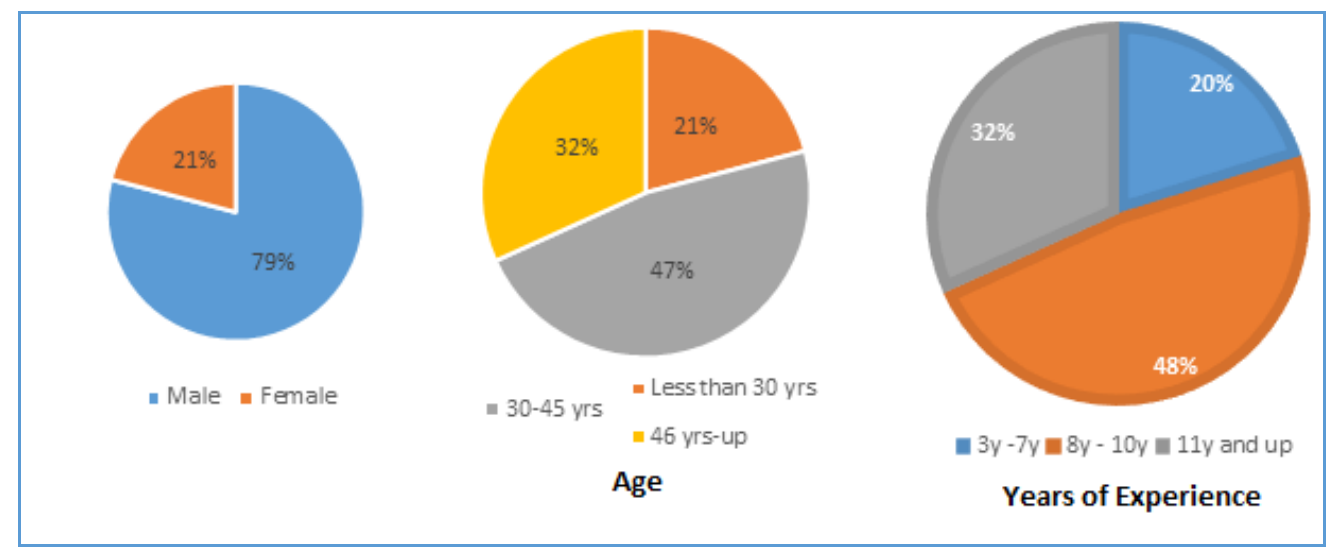

Fig. 7. Demography results

Data from Session\#2 was used to determine the average PM maturity level, in every knowledge areas, of these organizations as reported by the respondents. D is defined as the average project management maturity. Data suggested that D, of all said companies/ organization, is 2.99. On average D for the manufacturing sector is 3.30 , and that of the service sector is 2.87. From Table 5, and Figure 7, it is noted that in general, the manufacturing sector is better in project management maturity than the service sector. $83 \%$ of the manufacturing companies has a D between 3 and 4, while $94 \%$ of service companies has D between 2 and 3. These results are in line with Ibbs\&Kwak, [15], (2000) conclusions that, on a scale of 1 to 5 , these numbers indicate that there are still much space for improvement for these industries, especially the service sector.

Table 5: Average project management maturity level ranges

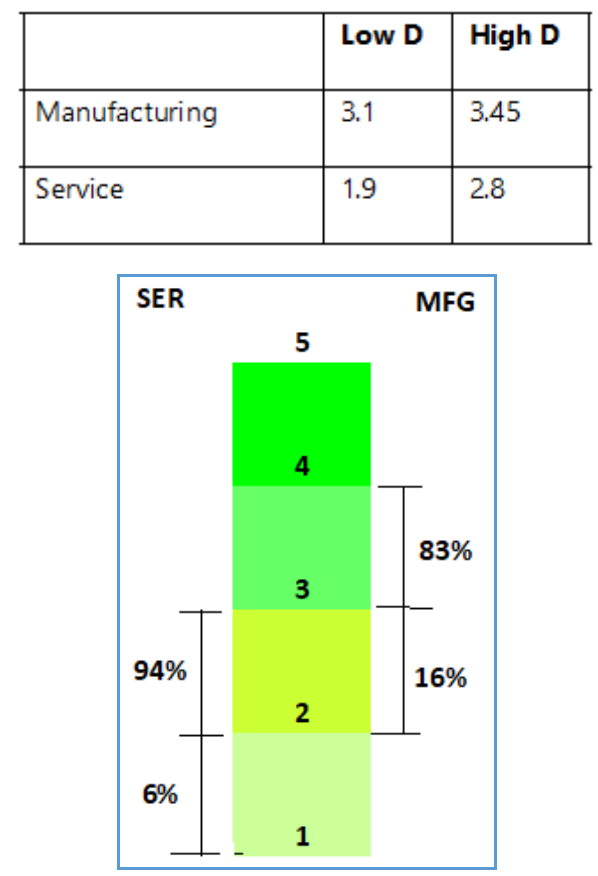

Figure 7: PMM Levels of Manufacturing and Service sectors

The average project management maturity, D, of T1 company is 3.35 and of T2 company are 3.24. Two manufacturing sector organizations, T3 and T4 achieved the highest average project management maturity level of 4.0 and one service sector company has the lowest average of 1.9. The construction management companies have the highest $\mathrm{D}$ of 4.0 .

Sixteen (12\%) out of the 129 participants in the survey work at the IT departments of their organizations. These sixteen also reported a higher average project management maturity level, (4.1). Computer Information Technology companies got the highest average project management maturity level of 4.2 . This suggests that 
the IT departments, as well as IT corporations, are more matured in project management. The least mature project management companies surveyed through our respondent belongs to the healthcare industry. As we have just two respondents from this industry the results are not conclusive. Health Industry rank lowest in project quality management (1.1) and risk management (1.0). On average both manufacturing and service, sectors are particularly weak in risk management maturity (2.5).

The two manufacturing companies, T1 and T2, related to the automotive industry, on average are more matured in communications (3.76) followed by scope (3.7) and quality management (3.69). The more matured of the two companies, (T1), is notably matured in project communication (3.66), scope (3.66), quality (3.51) and HR (3.43).
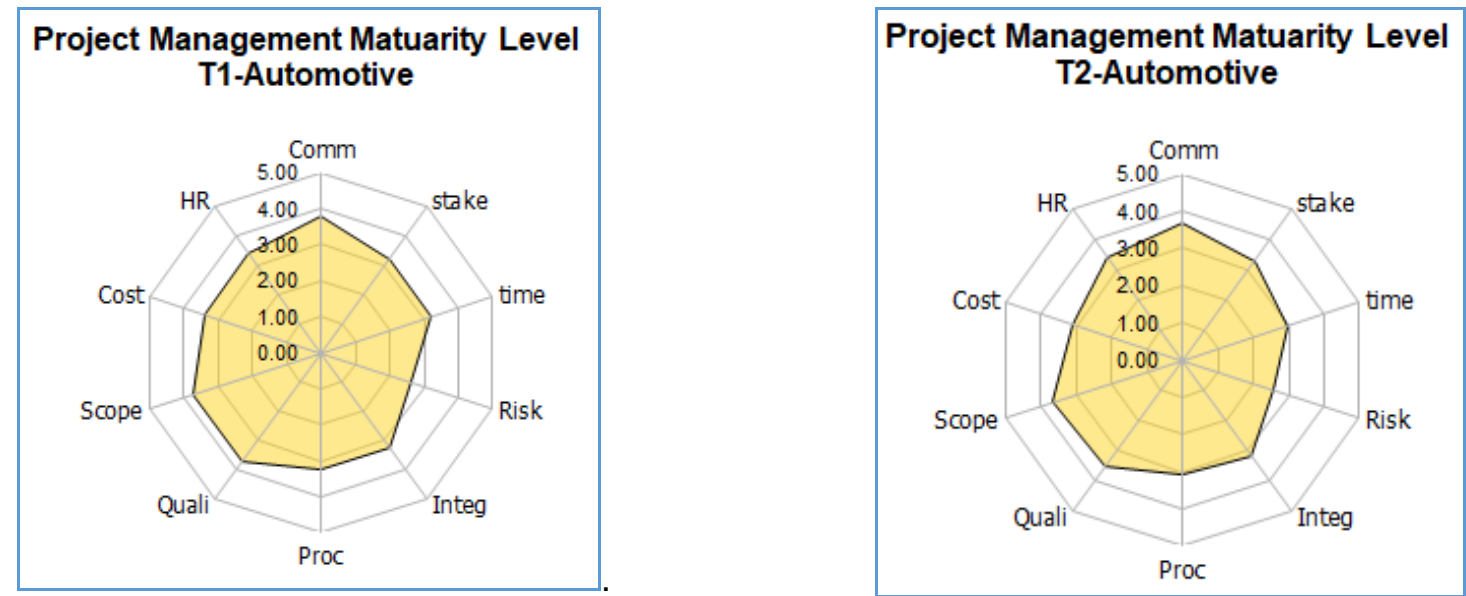

Figure 8: PMM levels for T1 and T2 manufacturing companies

The principal objective of this study is to validate the effect of various internal organizational dynamics on the outcome of project management maturity assessment. Data was collected and tabulated as per Table 6, where $\mathrm{I}_{\mathrm{i}}$ independent variables as defined in Table 2.

Table 6: Data collection table

\begin{tabular}{|c|c|c|c|c|c|c|c|c|c|c|c|c|c|c|c|}
\hline \multirow[t]{3}{*}{ Respondent } & \multicolumn{15}{|c|}{ D } \\
\hline & \multicolumn{4}{|c|}{$\begin{array}{c}\text { Without } \\
\text { Internal } \\
\text { Influences }\end{array}$} & \multicolumn{3}{|c|}{$\begin{array}{l}\text { With Internal } \\
\text { Influence } 1\end{array}$} & \multicolumn{4}{|c|}{$\begin{array}{l}\text { With Internal } \\
\text { Influence } 2\end{array}$} & \multicolumn{4}{|c|}{$\begin{array}{l}\text { With Internal } \\
\text { Influence } 3\end{array}$} \\
\hline & $\left.\right|_{1}$ & $\mathrm{I}_{2}$ & $\left.\right|_{3 . \ldots}$ & f & $l_{1}$ & $\left.\right|_{3 . . .}$ & f & $l_{1}$ & $\mathrm{l}_{2}$ & 13... & l & $l_{1}$ & 12 & 13. & $\mathrm{i}$ \\
\hline 1 & & & & & & & & & & & & & & & \\
\hline 2 & & & & & & & & & & & & & & & \\
\hline $\mathrm{n}$ & & & & & & & & & & & & & & & \\
\hline
\end{tabular}

The data from 67 respondent of T1 and T2 companies representing manufacturing sector is used to test hypothesis using paired samples. This require testing the project management maturity level, D, of manufacturing sector. Comparison were made between D with "no internal influence" and D with three internal influences. Table 7, illustrates that the internal influences like "organization culture" and "leadership" will result in an increase in the manufacturing sectors' project management maturity's levels. On the other hand, "emotional stability" actually, reduces it.

Table 7: Paired Samples Statistics 


\begin{tabular}{|ll|l|l|l|l|}
\hline & & Mean & $\mathbf{N}$ & Std. Deviation & Std. Error Mean \\
\hline Pair 1 & D-No Influence & 3.5746 & 67 & .44085 & .05386 \\
& D-OrgCulture & 4.0328 & 67 & .33230 & .04060 \\
Pair 2 & D-No Influence & 3.5746 & 67 & .44085 & .05386 \\
& D-Leadership & 4.0313 & 67 & .34650 & .04233 \\
Pair 3 & D-NoInfluence & 3.5746 & 67 & .44085 & .05386 \\
& D-Emotions & 3.2806 & 67 & .44150 & .05394 \\
\hline
\end{tabular}

The paired sample correlation, Table 8, indicates the highest effect on the values of project management maturity assessment's level comes from leadership influence $(0.883)$, followed by organization culture $(0.86)$ and emotional stability $(0.838)$.

Table 8: Paired samples correlations

\begin{tabular}{|c|c|c|c|}
\hline & $\mathbf{N}$ & Correlation & Sig. \\
\hline $\begin{array}{cl}\text { Pair } 1 & \text { D-Nolnfluence\& D- } \\
& \text { OrgCulture }\end{array}$ & 67 & .860 & .000 \\
\hline $\begin{array}{l}\text { Pair } 2 \text { D-Nolnfluence\& D- } \\
\text { Leadership }\end{array}$ & 67 & .883 & .000 \\
\hline Pair 3 D-Nolnfluence\& D-Emotions & 67 & .838 & .000 \\
\hline
\end{tabular}

Finally, the paired sample mean test (t-test) was performed on three different pairs to determine whether the mean difference between two sets of observations is zero.

1. Project management maturity level with no internal influences, (D-Nolnfluence), and project management maturity level with internal influence, organization culture, (D-OrgCulture)

2. Project management maturity level with no internal influences, (D-Nolnfluence), and project management maturity level with internal influence, Leadership, (D-Leadership)

3. Project management maturity level with no internal influences, (D-Nolnfluence), and project management maturity level with internal influence, behavioural excellence, (D-Emotion)

Table 9, suggests that the 2-tailed significance of all the three pairs (three hypothesis) are less than 0.05 , concluding that there is a statistical difference between conditions related in pairs, and that the maturity level assessments of the organizations are significantly affected by the internal factors. Thus, organization culture, leadership involvement, and workers emotional stability will skew the assessment results.

The next step is to conduct a detail analysis to identify the effect of these Organization Culture influences on PMMA especially, how these internal influences will effect the project management knowledge areas as access by PMMA process. The anslysis of organizational cultural effect on PMMA is presented here in detail while the leadership and emotional stability will be summerized at the end of the analysis.

Table 9: Paired samples test

\begin{tabular}{|c|c|c|c|c|c|c|c|c|c|}
\hline & & \multicolumn{5}{|c|}{ Paired Differences } & \multirow[b]{3}{*}{$\mathbf{t}$} & \multirow[b]{3}{*}{ df } & \multirow{3}{*}{\begin{tabular}{|l} 
Sig. (2- \\
tailed)
\end{tabular}} \\
\hline & & \multirow[b]{2}{*}{ Mean } & \multirow{2}{*}{$\begin{array}{c}\text { Std. } \\
\text { Deviation }\end{array}$} & \multirow{2}{*}{$\begin{array}{l}\text { Std. } \\
\text { Error } \\
\text { Mean }\end{array}$} & \multicolumn{2}{|c|}{$\begin{array}{l}\text { 95\% Confidence } \\
\text { Interval of the } \\
\text { Difference }\end{array}$} & & & \\
\hline & & & & & Lower & Upper & & & \\
\hline Pair 1 & D-Nolnfluence-D-OrgCulture & -.45821 & 22972 & 02807 & -.51424 & -.40218 & -16.327 & 66 & .000 \\
\hline Pair 2 & D-Nolnfluence - D-Leadership & -.45672 & 21122 & .02580 & -.50824 & -.40520 & -17.699 & 66 & .000 \\
\hline Pair 3 & D-Nolnfluence - D-Emotions & 29403 & 25099 & .03066 & 23281 & .35525 & 9.589 & 66 & .000 \\
\hline
\end{tabular}


Table 10, shows the multiple linear regression model summary and overall fit statistics. Five models are identified that can explain the variation in the data. The $5^{\text {th }}$ model, has the adjusted $R^{2}$ of 0.633 with the $R^{2}=$ 0.66. This means that the linear regression explains $66 \%$ of the variance in the data.

Table 10: Model Summary - Organization Culture Effect

\begin{tabular}{l|l|r|r|r|r|}
\hline Model & $\mathrm{R}$ & R Square & $\begin{array}{c}\text { Adjusted R } \\
\text { Square }\end{array}$ & $\begin{array}{c}\text { Std. Error of } \\
\text { the Estimate }\end{array}$ & $\begin{array}{c}\text { Durbin- } \\
\text { Watson }\end{array}$ \\
\hline 1 & $.537^{\mathrm{a}}$ & .288 & .277 & .15028 & \\
2 & $.682^{\mathrm{b}}$ & .465 & .448 & .13136 & \\
3 & $.763^{\mathrm{C}}$ & .582 & .562 & .11695 & \\
4 & $.788^{\mathrm{d}}$ & .622 & .597 & .11221 & \\
5 & $.813^{\mathrm{e}}$ & .660 & .633 & .10717 & 1.408 \\
\hline
\end{tabular}
a. Predictors: (Constant), DScopeCul
b. Predictors: (Constant), DScopeCul, DIntegCul
c. Predictors: (Constant), DScopeCul, DIntegCul, DQltyCul
d. Predictors: (Constant), DScopeCul, DIntegCul, DQItyCul, DRiskCul
e. Predictors: (Constant), DScopeCul, DIntegCul, DQltyCul, DRiskCul, DStakeCul

Table 11 shows the F-test for Model 5. The linear regression's F-test has the null hypothesis that the model explains zero variance in the dependent variable (in other words $\mathrm{R}^{2}=0$ ). The F-test is highly significant, thus we can assume that Model 5, explains a significant amount of the variance in PMMA.

Table 11: ANOVA - Organization Culture Effect

\begin{tabular}{|c|c|c|c|c|c|c|}
\hline & & $\begin{array}{l}\text { Sum of } \\
\text { Squares }\end{array}$ & df & Mean Square & $\mathrm{F}$ & Sig. \\
\hline \multirow[t]{3}{*}{5} & Regression & 1.362 & 5 & .272 & 23.724 & $.000^{f}$ \\
\hline & Residual & .701 & 61 & .011 & & \\
\hline & Total & 2.063 & 66 & & & \\
\hline
\end{tabular}

f. Predictors: (Constant), DScopeCul, DIntegCul, DQltyCul, DRiskCul, DStakeCul

The Coefficients table, Table 12, provides us with the necessary information to predict change in PMMA by the independent variables. The standardize coefficient of Scope is highest, (0.486), followed by Quality (0.367) and Integration (0.349). Risk Management and Stakeholder Management have lower but significant beta values. The information in the table 12 above also allows checking for multi-collinearity in the multiple linear regression model. In such cases, the tolerance should be $>0.1$ (or VIF $<10$ ) for all variables, which they are.

Table 12: Coefficients - Organization Culture Effect

\begin{tabular}{|c|c|c|c|c|c|c|c|c|}
\hline \multirow[b]{2}{*}{ Mode } & & \multicolumn{2}{|c|}{ Unstandardized Coefficients } & \multirow{2}{*}{$\begin{array}{c}\begin{array}{c}\text { Standardized } \\
\text { Coefficients }\end{array} \\
\text { Beta }\end{array}$} & \multirow[b]{2}{*}{$t$} & \multirow[b]{2}{*}{ Sig. } & \multicolumn{2}{|c|}{ Collinearity Statistics } \\
\hline & & $B$ & Std. Error & & & & Tolerance & VIF \\
\hline \multirow[t]{6}{*}{5} & (Constant) & .357 & .069 & & 5.163 & .000 & & \\
\hline & DScopeCul & .195 & .031 & .486 & 6.185 & .000 & .903 & 1.107 \\
\hline & DIntegCul & .158 & .035 & .349 & 4.558 & .000 & .948 & 1.055 \\
\hline & DQltyCul & .176 & .037 & .367 & 4.750 & .000 & .930 & 1.075 \\
\hline & DRiskCul & .121 & .045 & .204 & 2.670 & .010 & .950 & 1.053 \\
\hline & DStakeCul & .107 & .041 & .202 & 2.639 & .011 & .953 & 1.049 \\
\hline
\end{tabular}

The above analysis was repeated for calculating multi regression for PMMA effected by Leadership and Emotional stability and results are presented in Table 13. In this table, a zero indicates a zero effect of the internal influence on PMMA levels, while a double positive or negative has more affect than single positive or negative. So, a positive sign indicate that the internal influence will artificially increase the PMM level during the assessment process and vice-versa.

Table 13: Internal Influences effects on PMM Assessment 


\begin{tabular}{|l|c|c|c|}
\hline \multicolumn{1}{|c|}{ PM Knowledge Areas } & $\begin{array}{c}\text { Organization } \\
\text { Culture }\end{array}$ & $\begin{array}{c}\text { Leadership \& } \\
\text { Leadership } \\
\text { hierarchy }\end{array}$ & $\begin{array}{c}\text { Emotional } \\
\text { Stability }\end{array}$ \\
\hline Project Integration Management & $2+$ & 0 & 0 \\
\hline Project Scope Management & $3+$ & 0 & - \\
\hline Project Time Management & 0 & $3+$ & $2-$ \\
\hline Project Cost Management & 0 & $2-$ & 0 \\
\hline Project Quality Management & $2+$ & + & $2-$ \\
\hline Project Human Resource Management & 0 & - & 0 \\
\hline Project Communication Management & 0 & 0 & $2-$ \\
\hline Project Risk Management & + & + & $2-$ \\
\hline Project Procurement Management & 0 & 0 & 0 \\
\hline Project Stakeholders Management & + & $2+$ & 0 \\
\hline
\end{tabular}

\section{Conclusion and Discussion}

This research tries to investigate the effect of organizations internal influences on the project management maturity assessment levels. Using an amended existing PMM level assessment questionnaire, data was collected through 129 representatives of 40 different manufacturing and service organizations. A detailed analysis was conducted for the two primary manufacturing organizations with 67 respondents. The results indicate that the manufacturing sector, has higher project management maturity, (PMM), levels (3.35 and 3.24 respectively), while service sector has the lowest PMM level (1.4).

The second half of the research investigated the overall effect of Interval influences like, Organizational culture, Leadership \& Hierarchy and Emotional Stability. Based on the data analysis presented, it is concluded that in order to minimize the effects of

1. Organizational culture on PMMA levels, extra care should be taken when assessing the project scope management, project integration management, project quality management, project risk management and stakeholder management areas. These influences will positively skew the PMMA levels and give a higher PMMA level than usual.

2. Leadership and leadership hierarchy on PMMA levels, extra care should be taken when assessing the project time management, project quality management, project risk management and project stakeholder management as they will positively skew the PMM levels; while project cost management and project HRM will negative skew the PMMA and hence give a lower values then usual.

a. Lesson Learned: When upper management and managers place special importance to any project, it might create an additional visibility to the project. During the planning and management of such project, if the company is involved in the PMMA the results might not reflect the real levels.

3. Emotional stability on PMMA levels, extra care should be taken when assessing the project scope management, project time management, project quality management, project communication management, and project risk management. These influences will negatively skew the PMM levels and give a lower PMMA level than usual.

a. Lesson Learned: Low morale workers can create such adverse effect on the organization and any PMMA conducted during such time can result in a lower PMMA level than actual.

This study only touched a few of the internal factors. Several internal factors, including the external factors, were not considered that could illustrate a larger impact on maturity levels that could skew the results of any assessment currently in place. It is hard to make assertions about the validity (generalization) of this survey since only 129 people from 40 organizations participated in this research. However, the conclusions can be a great start for an extensive longitudinal study of multiple organizations. Such research needs to involve a wide range of industries. This should include investigating the overall effects of organizations' internal and external influences on PMMMA resulting in a new process and questionnaire for PMMA.

It might be too early to make changes in the project management maturity models and assessments methods based on this research. However, the changes raised in the UK Office of Government Commerce's, [16], the instrument can be a great start for a detailed study that can go beyond project management knowledge areas and concentrate on their components too. These influences are considered as confounding variables. It is 
also recommended that future research should focus on answering which of the predictors (main exposure and confounders) are the strongest predictor of outcome. Moreover, are the potential confounders really confounding the relationship between the outcome and the main exposure variable?

\section{Acknowledgments}

The author thanks the experts who have contributed towards the testing of the instrument and graduate students of Engineering Management and Quality Management who participated in the survey.

\section{References}

[1]. Institute, P. M., Project Management Institute, \& Books24x7, I. (2013). Organizational project management maturity model (OPM3®) - third edition (3rd;3; Ed.). Newtown Square, PA: Project Management Institute.

[2]. Fahrenkrog, S. L., Haeck, W., Abrams, F., \&Whelbourn, D. (2003). PMI's organizational project management maturity model. Paper presented at $\mathrm{PMI}{ }^{\circledR}$ Global Congress 2003-North America, Baltimore, MD. Newtown Square, PA: Project Management Institute.

[3]. Kerzner, H. (2004). Advanced project management. 2nd ed. Hoboken, NJ: John Wiley \& Sons, Inc.

[4]. Kerzner, H. R. (2013). Project management: A systems approach to planning, scheduling, and controlling(11th e.d.). New York, NY: John Wiley \& Sons, Inc.

[5]. Mullaly, M. (2006). Longitudinal analysis of project management maturity. Project Management Journal: Research Quarterly, 37(3), Retrieved from http://www.pmi.org/ /media/Members/Publications.ashx

[6]. Crawford, J. K. (2006). The project management maturity model. Information Systems Management, Fall 2006, 23(4). Retrieved from http://search.proquest.com.ezproxy.emich.edu.

[7]. Smith, D. A. (2010). Knowledge management as an indication of organizational maturity in project management: an enhancement of the opm3@ model. Capella University. April 2010. Retrieved from http://search.proquest.com.ezproxy.emich.edu.

[8]. Yazici, H. J. (2009). The role of project management maturity and organizational culture in perceived performance. Project Management Journal: Research Quarterly, 40(3), Retrieved from http://www.pmi.org/ /media/Members/Publications/ashx.

[9]. Riollano, C. C. (2012). Uniformity of organizational culture with the organizational project management maturity model: an exploratory investigation. Capella University. October 2012. Retrieved from http://search.proquest.com.ezproxy.emich.edu.

[10]. Saway, N \&Trapanese, P. (2004). Measuring project management maturity. Security Distributing and Marketing Magazine. January 2004, 34(1). Retrieved from http://search.proquest.com.ezproxy.emich.edu.

[11]. Khalema, L.S., van Waveren, C.C., \& Chan, K.-Y. (2015). The relationship between project management office maturity and organizational project management maturity: An empirical study of the South African government infrastructure departments. South African Journal of Industrial Engineering, 26(3), 12-26. https://dx.doi.org/10.7166/26-3-1021.

[12]. CBP Research 2007. State of the PMO 2007-2008. Havertown. PA: Taylor \& Francis Group

[13]. Jiang, J.J., Klein, G., Hwang, H.-G., Huang J. \& Hung, S.-Y. 2004. An exploration of the relationship between software development process maturity and project performance. Information \& Management, 41(3), pp 279-288.

[14]. Humphrey, W.S., Managing the Software Process, Addison-Wesley, Reading, MA, 1989.

[15]. Ibbs, C. W. \&Kwak, Y.-H. (2000). Assessing project management maturity. Project Management Journal, 31(1), 32-43.

[16]. UK, Office of Government Commerce. (2008). P3M3 v2.0 Self Assessment. Retrieved July 1, 2017, from http://www.strategies-for-managing-change.com/support-files/maturity-model-self-assessment.pdf. 